\title{
Geociências
}

\section{Arcabouço cronoestratigráfico da Formação Mafra (intervalo médio) na região de Rio Negro/PR - Mafra/SC, borda leste da bacia do Paraná}

\author{
Luiz Carlos Weinschütz \\ Doutorando em Geologia Regional.UNESP-IGCE, Rio Claro/SP. - E-mail: luizcwei@ibest.com.br \\ Joel Carneiro de Castro \\ UNESP-IGCE, Rio Claro/SP - E-mail: jocastro@rc.unesp.br
}

\section{Resumo}

Esse trabalho investiga a porção média da Formação Mafra (Grupo Itararé) na região de Mafra(SC)-Rio Negro(PR). Uma sondagem com 40m testemunhados (PM6), adjacente a uma grande pedreira com $70 \mathrm{~m}$ de altura, fornece, em conjunto, quase $100 \mathrm{~m}$ de seção, dominada por varvitos e diamictitos, representativa do Mafra-Médio. Recobrindo erosivamente esse intervalo, a mesma pedreira expõe $20 \mathrm{~m}$ de arenitos sigmoidais, já caracterizando a unidade Mafra-Superior. A Formação MafraMédio consiste de ciclos de granocrescência ascendente (varvito a diamictito), recobertos por um complexo ciclo granodecrescente (arenito-diamictito-varvito), atribuído a eventos de deglaciação; esse evento culmina com a deposição de siltito fossilífero marinho, que, ao contrário das demais fácies, não tem clastos caídos (dropstones).

As complexas relações laterais que marcam o ciclo/ evento de deglaciação podem ser documentadas em uma seção estratigráfica com cinco afloramentos. A base do evento é erosiva, fornecendo calhas que acomodam localmente grandes espessuras; tal sucessão transgressiva, desenvolvida com a deglaciação, deve-se ao recuo progressivo das geleiras. O intervalo médio da Formação Mafra representa um trato de sistemas transgressivo/de nível de base alto de uma seqüência deposicional de $3^{\text {a }}$ ordem, junto com os arenitos e siltitos do Mafra-Inferior, estes constituindo o trato de sistemas de nível baixo.

Palavras-chave: Sedimentação Glacial, Estratigrafia de Seqüências, Grupo Itararé, Bacia do Paraná, Permocarbonífero.

\begin{abstract}
The middle interval of Mafra Formation (Itararé Group) has been investigated in the Mafra-Rio Negro area, eastern margin of Paraná basin. The 40m-cored section of well PM-6, drilled at the foot of the 70m-high Motocross Quarry, provide a 90m-composite column representative of middle-Mafra Formation. This interval is unconformably overlain by sigmoidal sandstones of the upper part of Mafra Formation, as displayed in the same quarry. Two types of cycles are found in middle Mafra. Several coarsening-upward cycles composed of varvites, massive sandstones/siltstones (local) and diamictites, are followed by a major fining-upward cycle, formed by sandstone, diamictite and varvite. Pebble to boulder-size dropstones occur in all facies.
\end{abstract}

The upper FU-cycle, designated as deglaciation facies/cycle, has a complex distribution of thickness and constituent lithofacies. Local depocenters of the cycle are related to lows escavated by glaciers; they were filled by sediments derived from the receeding ice, in a classical, transgressive setting related to deglaciation. The middle-Mafra Formation forms the upper, transgressive-highstand system tracts of a depositional sequence, together with sandstones and diamictites of the lower, lowstand system tracts of lower Mafra Formation.

Keywords: Glacial Sedimentation, Sequence Stratigraphy, Itararé Group, Paraná Basin, Permocarboniferous. 
Arcabouço cronoestratigráfico da Formação Mafra (intervalo médio) na região de Rio Negro/PR ...

\section{Introdução}

O Grupo Itararé guarda o mais importante registro de glaciação da história da Terra, desenvolvido em todo o Gondwana no Permocarbonífero. Na carta estratigráfica de Schneider et al.(1974), o Grupo Itararé foi dividido, na faixa aflorante sul- paranaense e catarinense, nas formações Campo do Tenente, Mafra e Rio do Sul.

Por outro lado, o Grupo Itararé, para França e Potter (1988), consiste de três formações, que representam três ciclos de argilosidade crescente para cima: Lagoa Azul, cuja parte superior corresponde à Formação Campo do Tenente; Campo Mourão, correspondente à Formação Mafra; e Taciba, correpondente à Formação Rio do Sul.

Uma pequena mas importante diferença entre as duas cartas pode ser notada na unidade superior do Grupo Itararé. Enquanto Schneider et al. (1974) incluem o "Membro Lontras", uma unidade de folhelhos e argilitos várvicos, na base de sua Fm. Rio do Sul, França e Potter (1988) posicionam o "Folhelho Lontras" no topo da Fm. Campo Mourão, representando a culminância fina/ argilosa de seu segundo ciclo (Campo Mourão). Ainda, esses autores chamam de Fm. Taciba ao ciclo superior do Grupo Itararé, nele destacando um nível arenoso basal (Mb. Rio Segredo) e dois membros principais, Chapéu do Sol (diamictito) e Rio do Sul (folhelho e ritmito fino).

Na região de Rio Negro (PR) - Mafra (SC), ocorre uma das mais importan- tes e clássicas seções aflorantes do Grupo Itararé, que inclui os estratótipos das formações Campo do Tenente e Mafra (Schneider et al., 1974). Em sua dissertação de mestrado, Weinschütz (2001) identifica três divisões em cada uma das formações Mafra e Rio do Sul, divisões estas que o autor interpreta como pertencentes a três seqüências deposicionais (Tabela 1).

Vale dizer que tais seqüências aproximam-se dos ciclos/Formações Campo Mourão e Taciba de França e Potter (1988), exceto quanto à subdivisão do ciclo/Formação Campo Mourão em duas seqüências.

Em 2003, a região de Rio Negro e Mafra teve seu acervo científico enriquecido com a perfuração de seis poços, tendo profundidade média de $60 \mathrm{~m}$, executados pela Geosol e sob a iniciativa da Fundação Victor Dequech. Esses poços foram adequadamente locados, objetivando amostrar significativamente as formações Mafra e Rio do Sul e procurando compor os poços com seções de superfície. Assim, a sondagem denominada PM-6, com 40m de testemunhagem, foi locada no piso da maior pedreira da região, com $70 \mathrm{~m}$ de altura (ponto 6 , Figura 1$)$; isto possibilitou amostrar um total de $90 \mathrm{~m}$, representativos do intervalo médio da Formação Mafra (os demais $20 \mathrm{~m}$, do topo da pedreira, pertencem ao intervalo superior da Formação Mafra).

Esse é o primeiro de três artigos, que apresentarão os resultados das son- dagens e das respectivas seções contíguas de superfície; esse artigo trata do intervalo médio da Formação Mafra, bem como de sua interpretação no contexto da segunda seqüência deposicional do Grupo Itararé na área (Mafra-Médio/Inferior, sucedendo a seqüência da Formação Campo do Tenente).

Outro desafio da presente pesquisa é a definição de um arcabouço de Estratigrafia de Seqüências em contexto glacial, tema ainda pouco desenvolvido (Castro,1995).

\section{Materiais e métodos}

Seis sondagens testemunhadas foram executadas na área, sendo que a última delas abrangeu o intervalo médio da Formação Mafra e é objeto do presente estudo. Tal sondagem, PM-6 (Pedreira "Motocross", sondagem 6), testemunhou de 6 a $46 \mathrm{~m}$ de profundidade, tendo início no piso basal da grande pedreira homônima; nessa estão expostos quase $55 \mathrm{~m}$ do restante da Formação Mafra-Médio e também pelo menos 20m de arenitos sigmoidais da Formação Mafra-Superior (ponto 6, Figura 1).

Outros quatro grandes afloramentos do Mafra-Médio, pontos 7 a 10, são correlacionados à Pedreira Motocross e proporcionam um entendimento das complexas relações faciológicas daquela unidade.

Na sondagem PM-6 e nos cinco pontos aflorantes foram confeccionados

Tabela 1 - Correlação litoestratigráfica do Grupo Itararé com seqüências deposicionais definidas nesse trabalho.

\begin{tabular}{|c|c|c|c|}
\hline $\begin{array}{l}\text { Schneider et al. } \\
\qquad(1974)\end{array}$ & $\begin{array}{l}\text { França \& Potter } \\
\text { (1988) }\end{array}$ & $\begin{array}{l}\text { Weinschütz } \\
\text { (2001) }\end{array}$ & Seqüências \\
\hline \multirow[t]{2}{*}{ Fm, Rio do Sul (RS) } & Ciclo/Fm. Taciba & $\begin{array}{l}\text { Sup. (s): Siltito e folhelho } \\
\text { Méd. (m): diamictito, arenito e siltito }\end{array}$ & $\begin{array}{l}\text { Seqüência Rio do Sul } \\
\qquad \mathbf{s} / \mathbf{m}\end{array}$ \\
\hline & \multirow{3}{*}{ Ciclo/Fm. Campo Mourão } & Inf. (I): folhelho "Lontras" & Seqüência Rio do \\
\hline \multirow[b]{2}{*}{ Fm. Mafra (M) } & & Sup. (s): arenito e diamictito & Sul i/Mafra s \\
\hline & & $\begin{array}{l}\text { Méd. (m): varvito, diamictito e arenito } \\
\text { Inf. (I): arenito e diamictito }\end{array}$ & $\begin{array}{l}\text { Seqüência Mafra } \\
\text { m/i }\end{array}$ \\
\hline $\begin{array}{l}\text { Fm. Campo do Tenente } \\
\text { (CT) }\end{array}$ & Ciclo/Fm. Lagoa Azul & $\begin{array}{l}\text { Folhelho, varvito e diamictito } \\
\text { marron-avermelhado }\end{array}$ & $\begin{array}{l}\text { Seqüência Campo do } \\
\text { Tenente }\end{array}$ \\
\hline
\end{tabular}


perfis sedimentológicos verticais, com a identificação seqüencial de litologias, texturas e estruturas. Isso possibilita a caracterização de fácies/associações faciológicas e, através da análise de sucessões verticais de fácies, chega-se a padrões relacionados a tratos de sistemas e daí a seqüências deposicionais.

\section{Sondagem PM-6}

A sondagem PM-6, locada no piso basal da Pedreira Motocross, testemunhou 40m da Formação Mafra - intervalo médio. Esse intervalo se completa com a coluna presente na grande pedreira, adjacente à sondagem (ver adiante).

Três associações faciológicas ocorrem no poço PM-6: varvito (Vv), arenitosiltito (AS) e diamictito (D) (Figura 2).

Os varvitos $(\mathbf{V v})$ ocorrem em três posições da sondagem, com $8 \mathrm{~m}$ de espessura na base (Figura 3), 2m no meio e $6 \mathrm{~m}$ para o topo, onde se intercalam com diamictitos. Têm cor predominantemente marrom e exibem freqüentes clastos caídos com até $5 \mathrm{~mm}$ (dropstones); a descrição dessa fácies será completada na pedreira adjacente, onde a mesma atinge $40 \mathrm{~m}$ de espessura.

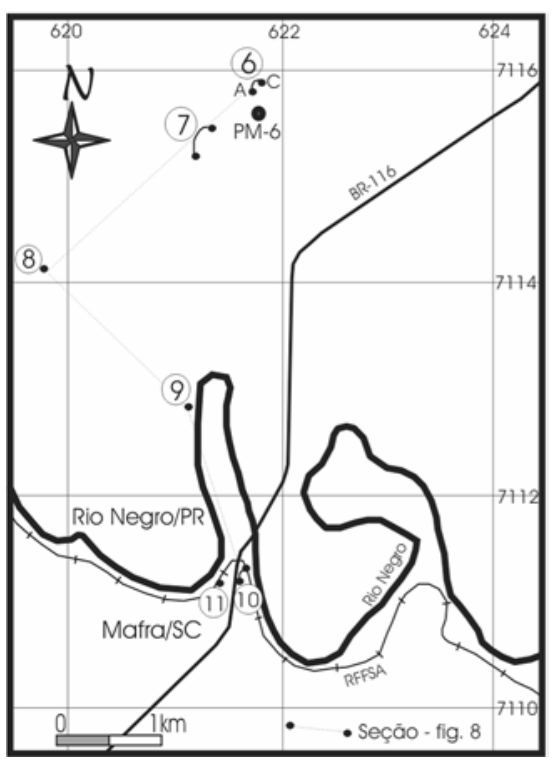

Figura 1 - Mapa de localização da área estudada, com a sondagem PM-6 e os afloramentos estudados.
A associação arenito-siltito (AS) sucede aos varvitos basais do PM-6, em contato aparentemente gradacional (Figura 3). Aquelas litologias apresentamse maciças, ou exibem feições de escorregamento e microfalhas; alguns arenitos formam estratos amalgamados, com espessura individual de $6,5 \mathrm{~cm}$ (Figura 4). No topo do intervalo, destaca-se um corpo métrico de arenito fino/médio, maciço (Figura 2). O principal processo parece ser o de liquefação (slurry), responsável pelas estruturas presentes; seixos caídos de até $2,5 \mathrm{~cm}$ revelam a contribuição de geleiras flutuantes.

A fácies diamictito (D) ocorre como dois corpos espessos, respectivamente com $8 \mathrm{~m}$ e $5 \mathrm{~m}$, sobreposto à associação anterior (Figura 2). Tem aspecto maciço e cores acastanhada(corpo inferior, Figura 5) e cinza (corpo superior); seixos caídos são freqüentes alcançando até

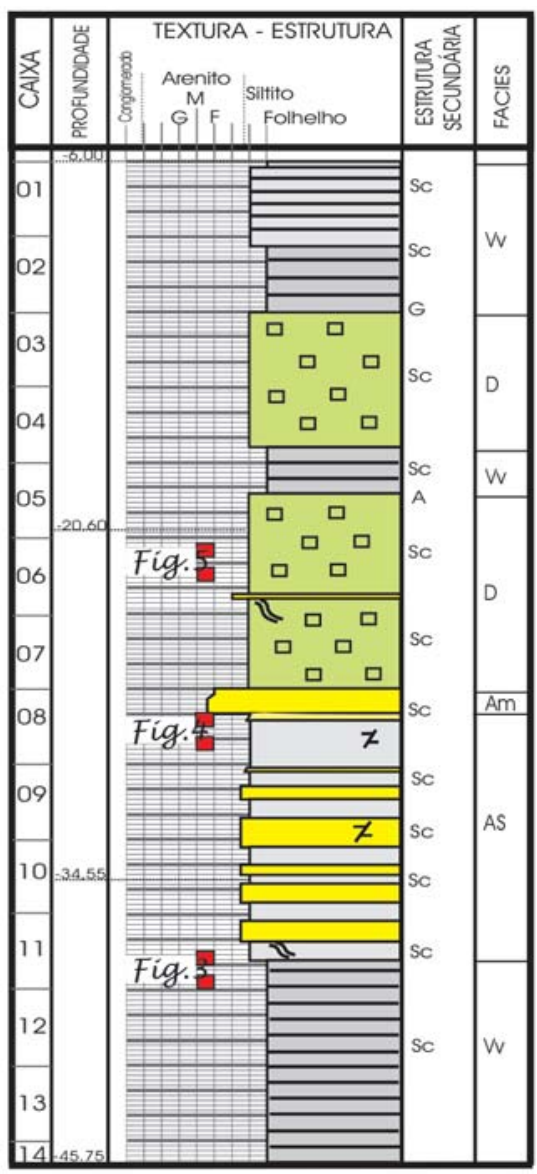

Figura 2 - Perfil sedimentológico do poço PM-6; ver símbolos na Figura 8.
$8 \mathrm{~cm}$ de diâmetro (calhau, cobble). Feições de escorregamento e ocasional presença de arenito maciço (Figura 5) sugerem parentesco com a associação (AS); no entanto, os diamictitos exibem maior influência glacial em sua deposição.

\section{Pedreira}

\section{Motocross - ponto 6}

A "Pedreira Motocross" tem aproximadamente $70 \mathrm{~m}$ de altura e é bastante complexa, principalmente no que se refere à associação de deglaciação (Dg)

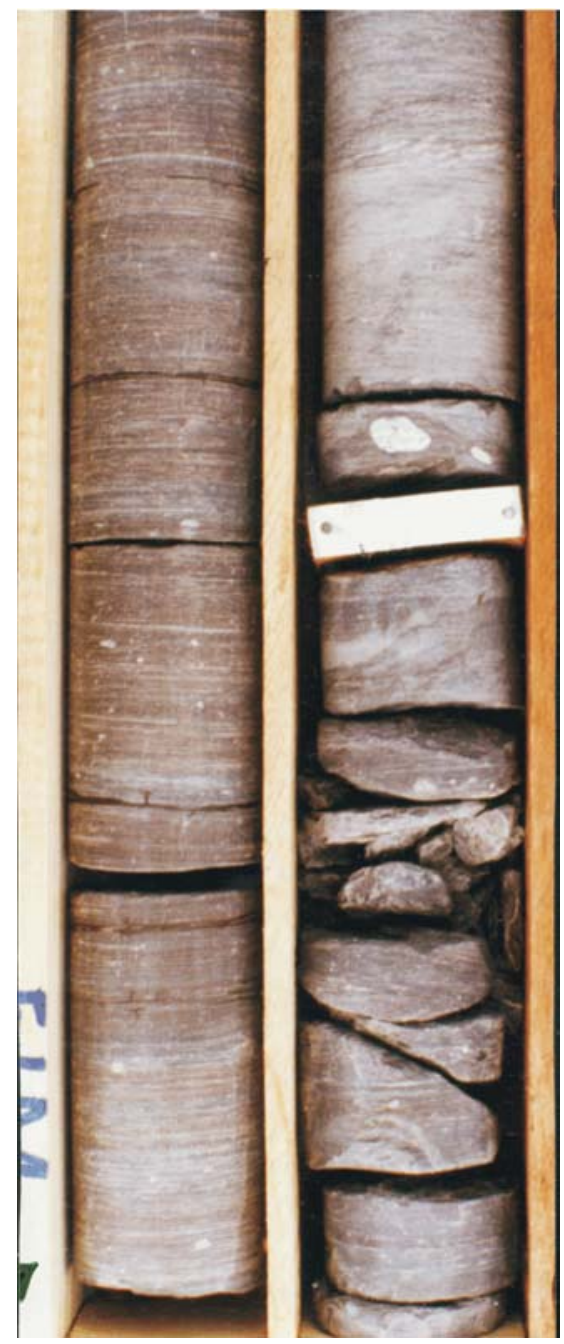

Figura 3 - Varvitos, Vv (raia esquerda), sobrepostos gradacionalmente por Siltitos e Arenitos, AS (raia direita); clastos caídos são comuns nas duas fácies. Largura dos testemunhos é sempre 3 " $(7,5 \mathrm{~cm})$; ver Figura 2 para localização. 
presente em sua parte superior (Figura 6). A pedreira consta de duas bancadas, referidas como sudoeste (ponto A) e nordeste (pontos B e C); a extensão entre $\mathrm{A}$ e $\mathrm{C}$ atinge aproximadamente $250 \mathrm{~m}$ (Figuras 1,6). Quatro associações faciológicas ocorrem na pedreira (base ao topo): varvito, siltito/folhelho, deglaciação e arenito sigmoidal. Esse último, (As), recobre erosivamente a associação de deglaciação (Dg) e já pertence ao intervalo superior da Formação Mafra.

Varvito (Vv). Nessa pedreira está a maior possança dessa fácies encontrada na área com quase 40m (Figura 7A). A grande maioria desses ritmitos regulares arenito-folhelho mostra: (a) pares delgados de espessura variando entre 1,5mm, 3mm (Figura 7B) e 9mm; (b)base abrupta da fração arenosa (clara) e passagem abrupta dessa para a fração pelítica (escura); (c) numerosos clastos caídos, geralmente contidos nas camadas claras.

Destaca-se ainda, no terço inferior da pedreira, um intervalo $=$ marco contendo três estratos com aleitamento gradacional (Figura 7A): o estrato basal tem $0,6 \mathrm{~m}$ e os demais têm $0,25 \mathrm{~m}$ cada. Notase, em cada um, incipiente laminação, na fração arenosa, e que se torna mais marcante no siltito, bem como clastos caídos de variados tamanhos, incluindo matacões. Os três estratos constituem eventos turbulentos de grande intensidade, interrompendo a sedimentação gláciolacustre normal dos varvitos.

Siltito/folhelho (S). Essa fácies pelítica está bem representada na extremidade direita da bancada sudoeste, sobrepondo-se aos varvitos (perfil A, Figura 6): são siltitos argilosos, esverdeados, finamente laminados. Na extremidade da bancada NE (perfil C) já ocorrem clastos caídos nos siltitos. Tal fácies também ocorre no perfil vizinho (ponto 7 , ver adiante).

Deglaciação (Dg). Essa complexa associação é formada por uma sucessão de arenitos com estruturas tracionais (estratificação e laminação cruzadas), que passam acima a arenitos lamíticos seixosos e a diamictitos (perfil A); essas mesmas litologias, encimadas por varvitos, formam dois ciclos de afinamento ascendente (perfil B), resultado de processo de deglaciação. Na seção entre os perfis $\mathrm{B}$ e C, é expressivo o truncamento lateral de litofácies do perfil B, bem como o contato abrupto do arenito basal com o siltito subjacente (X, Figura 6) de algumas das litofácies constituintes,

Arenito sigmoidal (As). Truncando erosivamente a associação faciológica anterior (Y, Figura 6), observa-se uma espessa seção de arenitos finos/médios com estratificação sigmoidal, já representando o intervalo superior da Formação Mafra; tal seção tem origem fluvial ou flúvio-deltaica, e constitui a parte basal da seqüência Mafra-Superior-Folhelho Lontras (Tabela 1).

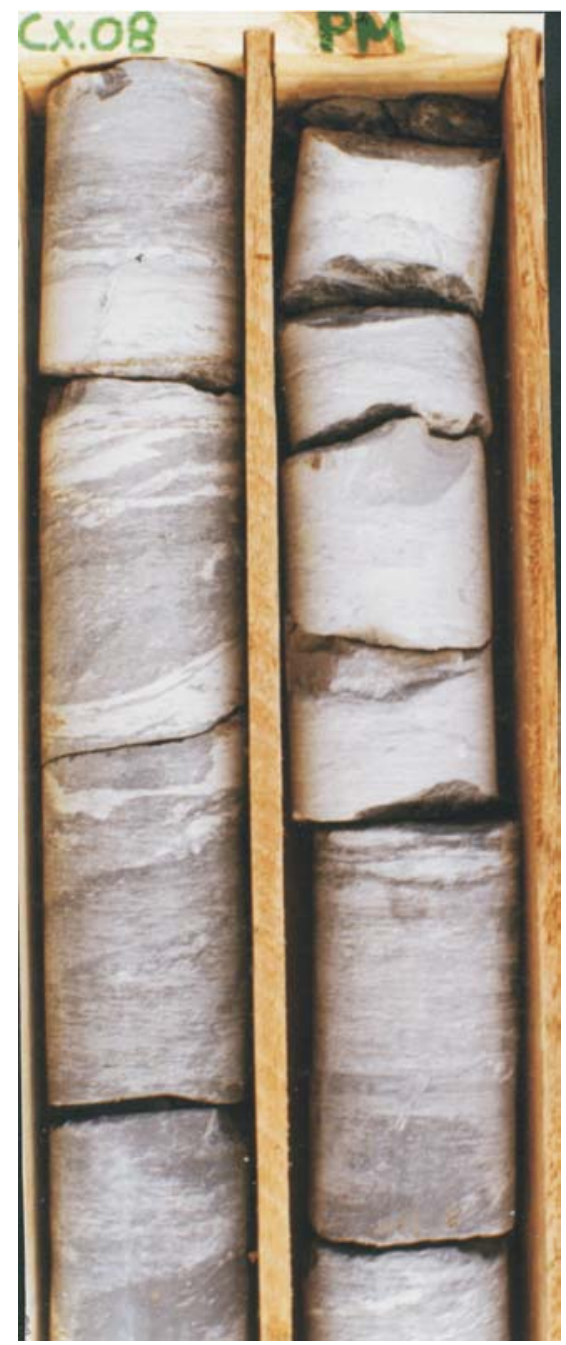

Figura 4 - Siltitos (raia esquerda) recobertos por arenitos maciços (parte superior da raia direita; fácies $\mathbf{A S}$ ).

\section{Arcabouço da Formação Mafra - Intervalo Médio}

A seção da Figura 8, tendo como datum o contato entre os intervalos superior e médio da Formação Mafra, revela a grande complexibilidade estratigráfica do intervalo médio, que inclui uma fácies de siltito fossilífero no topo do intervalo (Sf), entre os pontos 8 e $10 \mathrm{da}$ Figura 8. O perfil do ponto 6 foi acrescido com o perfil da sondagem PM-6, notando-se, entre os dois, um pequeno intervalo não recuperado pela sondagem.

Tal coluna do intervalo médio da Formação Mafra (quase 100m) é forma-

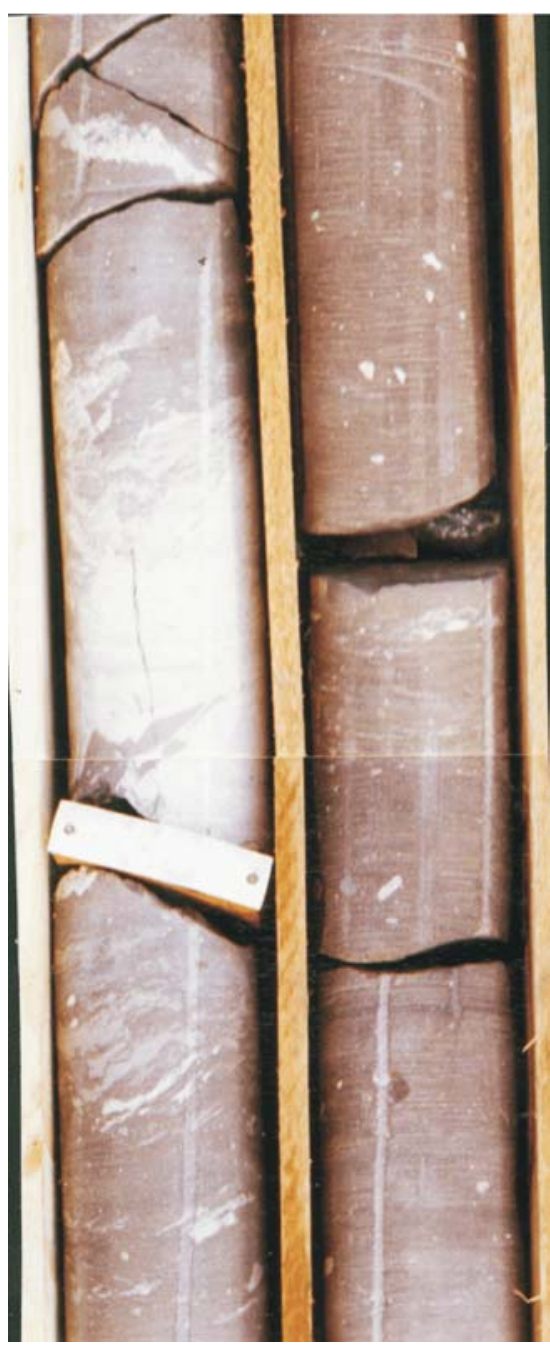

Figura 5 - Escorregamento (base da raia esquerda) e lente arenosa (meio da raia esquerda) dentro da fácies Diamictito, D (raia direita).

154 REM: R. Esc. Minas, Ouro Preto, 57(3): 151-156, jul. set. 2004 
da de dois ciclos principais (base ao topo): um de granocrescência ascendente, com varvito seguido de diamictito, e outro de granodecrescência ascendente (deglaciação), com a sucessão arenitodiamictito-varvito. Esse último pode ser encerrado por um corpo de siltito fossilífero (fácies Sf), que culmina o ciclo de deglaciação, de natureza transgressiva (Machado,1989; Castro, 1991). Pelo menos três sucessões de granocrescência ocorrem no poço PM-6: a basal é mais completa, pois inclui a associação arenito - siltito (AS) entre o varvito $(\mathbf{V v})$ e o diamictito (D).

Nos afloramentos dos pontos 8 a 10 , nota-se o grande desenvolvimento desse tipo de ciclo, estratigraficamente acima da seção do poço PM-6: trata-se da espessa seção de varvito (quase $40 \mathrm{~m}$ no ponto 6), recoberta por corpo de diamictito igualmente espesso (quase $30 \mathrm{~m}$ no ponto 8). Este último provavelmente tem uma base erosiva, que é provavelmente responsável pela depressão necessária para acomodar o diamictito (eixo no ponto 8, Figura 8). A sucessão dessas fácies revela uma evolução de processos glaciais distintos, de varves sazonais(varvito) para suspensão - chuva de detritos (diamictito rain-out), talvez refletindo uma crescente proximidade das frentes de geleiras (Canuto, 1985; Weinschütz, 2001).

É notável o evento de deglaciação representativo do fim do ciclo glacial Mafra-Médio. Sua maior possança é notada no ponto 7 , localizado a apenas $700 \mathrm{~m}$ a sudoeste do ponto 6 ; na correlação entre os dois pontos, reconhecemse duas sucessões granodecrescentes, onde a maior espessura no ponto 7 revela o maior espaço de acomodação disponível nesse local (originado pelo maior efeito erosivo do substrato pelas geleiras em recuo).

Tal efeito erosivo da fase de deglaciação é ainda mais dramático ao longo da ferrovia RFFSA (Figura 1), onde os varvitos expostos sob o viaduto da BR116, ponto 10, encontram-se erodidos uma centena de metros adiante, no ponto 11 da mesma ferrovia. Aqui aflora um

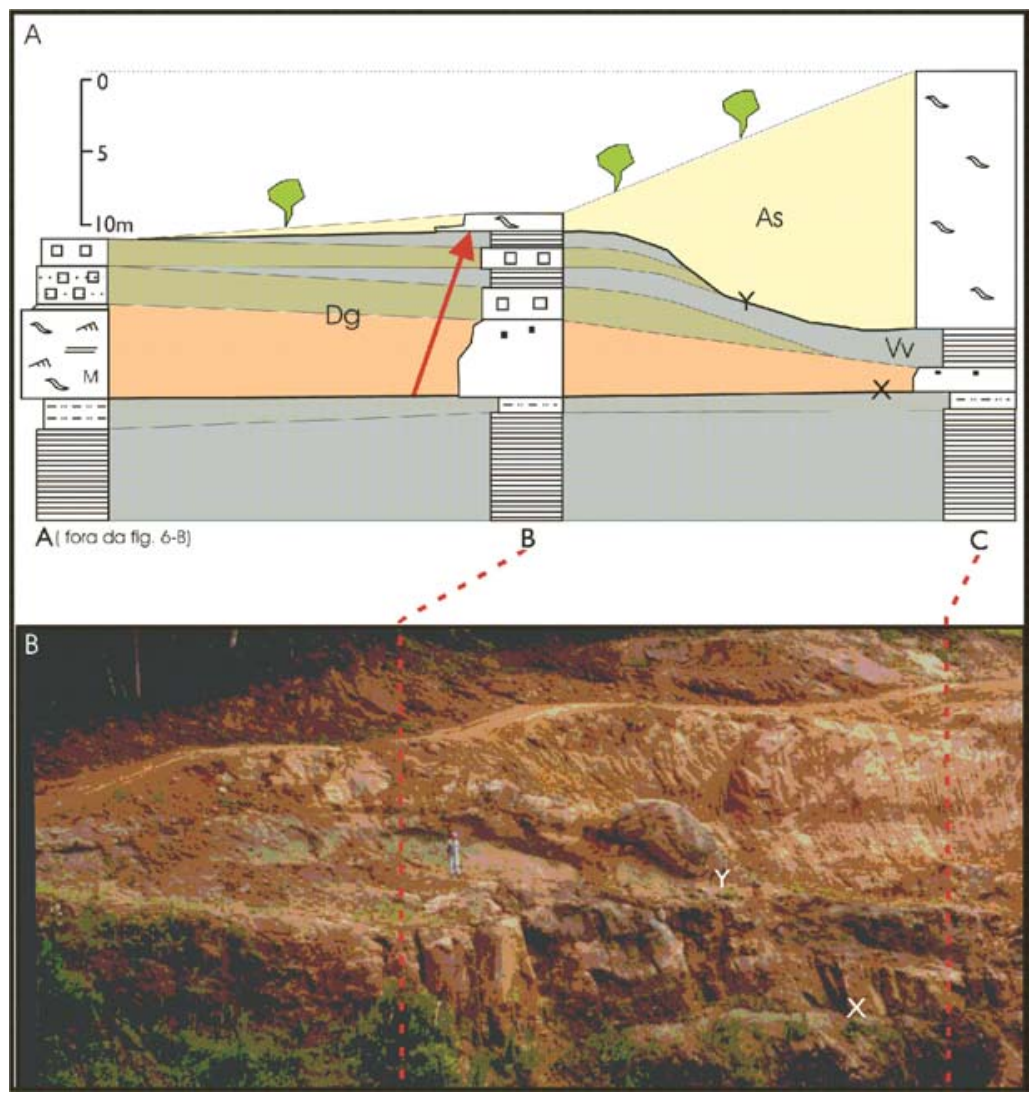

Figura 6 - A) Parte superior da pedreira Motocross, destacando as fácies de deglaciação, Dg, e arenito sigmoidal, As (quadrante superior esquerdo).B) Esquema da foto acima, destacando as superfícies erosivas $\mathbf{X}$ e $\mathbf{Y}$ que limitam as fácies $\mathbf{D g}$ e As; ver símbolos na Figura 8.

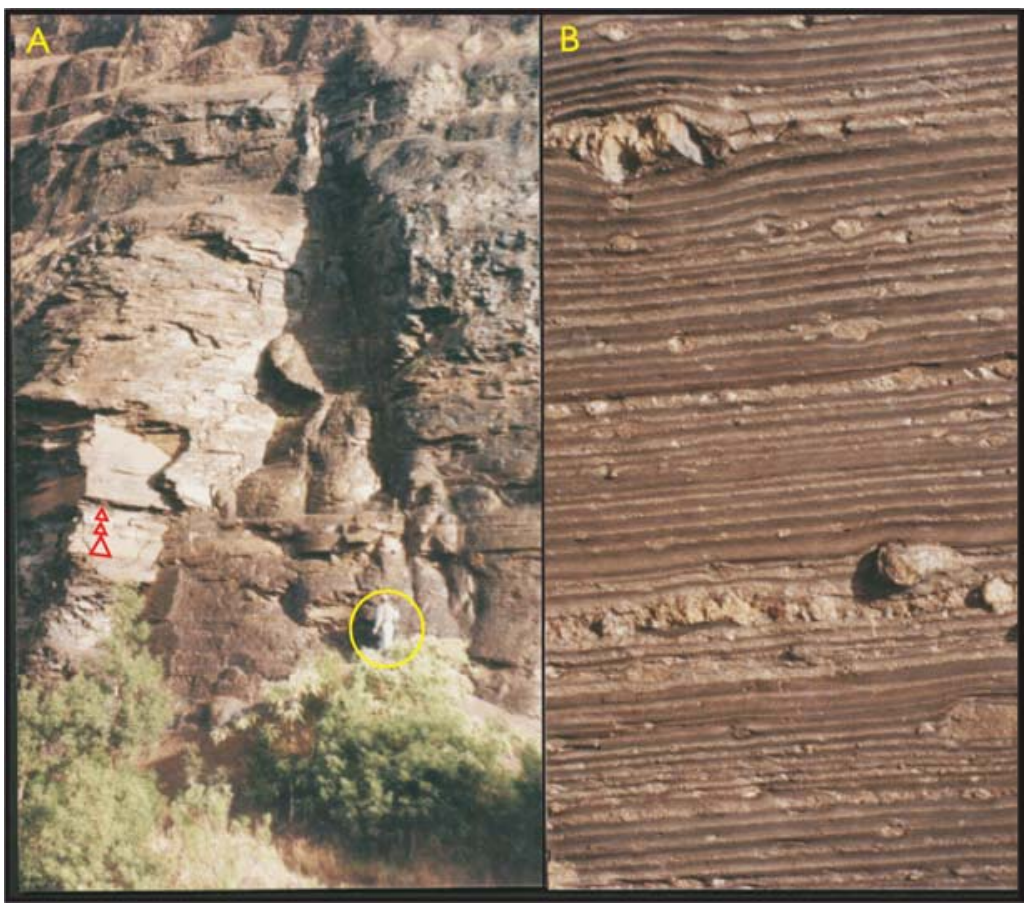

Figura 7 - A) Vista geral da fácies Varvito, Vv, que forma a parte superior da Pedreira Motocross (figura humana como escala). Triângulos vermelhos indicam estratos com aleitamento gradacional, caracterizando eventos turbulentos em meio à sedimentação normal dos varvitos. B) Detalhe dos varvitos, com clastos caídos nas lâminas claras. Altura da amostra: $21 \mathrm{~cm}$. 
espesso intervalo de conglomerados/ arenitos seixosos encimados por diamictitos, assim constituindo um eixo erosivo preferencial para a deglaciação.

Finalmente, o expressivo evento marinho de siltito fossilífero (Sf, Figura 8), portador de braquiópodes, gastrópodes, escamas de peixes e foraminíferos arenáceos, encerra o ciclo transgressivo da deglaciação, representativo da Formação Mafra - Intervalo Médio.

\section{Conclusões}

Seis fácies/associações faciológicas foram identificadas em sondagem (PM-6) e afloramentos da Formação Mafra - Intervalo Médio: varvito (Vv), arenito-siltito (AS), diamictito (D), siltito-folhelho (S), deglaciação (Dg) e siltito fossilífero (Sf).

As três primeiras, ou, mais comumente, as fácies (Vv) e (D), formam sucessões de granodecrescência ascendente, refletindo uma evolução de processos gravitacionais (suspensão, liquefação-slurry, e suspensão-chuva de detritos) e, provavelmente, indicando uma crescente proximidade dos gelos flutuantes (icebergs). A fácies (S), geralmente sobreposta aos varvitos, localmente lembra a fácies marinha (Sf), mas é portadora de clastos caídos como as demais.

A associação de deglaciação (Dg) é, sem dúvida, a mais complexa e constitui a parte superior da unidade estudada: é formada por um ciclo granodecrescente de arenito-diamictito-varvito, dentro de um contexto transgressivo de recuo de geleiras, que culmina com o siltito fossilífero ( $\mathbf{S f}$ ) clássico na área. A associação (Dg) mostra uma base fortemente erosiva, propiciando a escavação de canais necessários para acomodar a respectiva sedimentação (por exemplo, nos pontos 7 e 11, este próximo ao ponto 10).

Toda a sedimentação do MafraMédio, dominada por varvitos e diamictitos, constitui um trato transgressivo/ de nível de base alto de uma seqüência, que se completa com a seção arenosa e diamíctica do Mafra-Inferior (trato de ní-

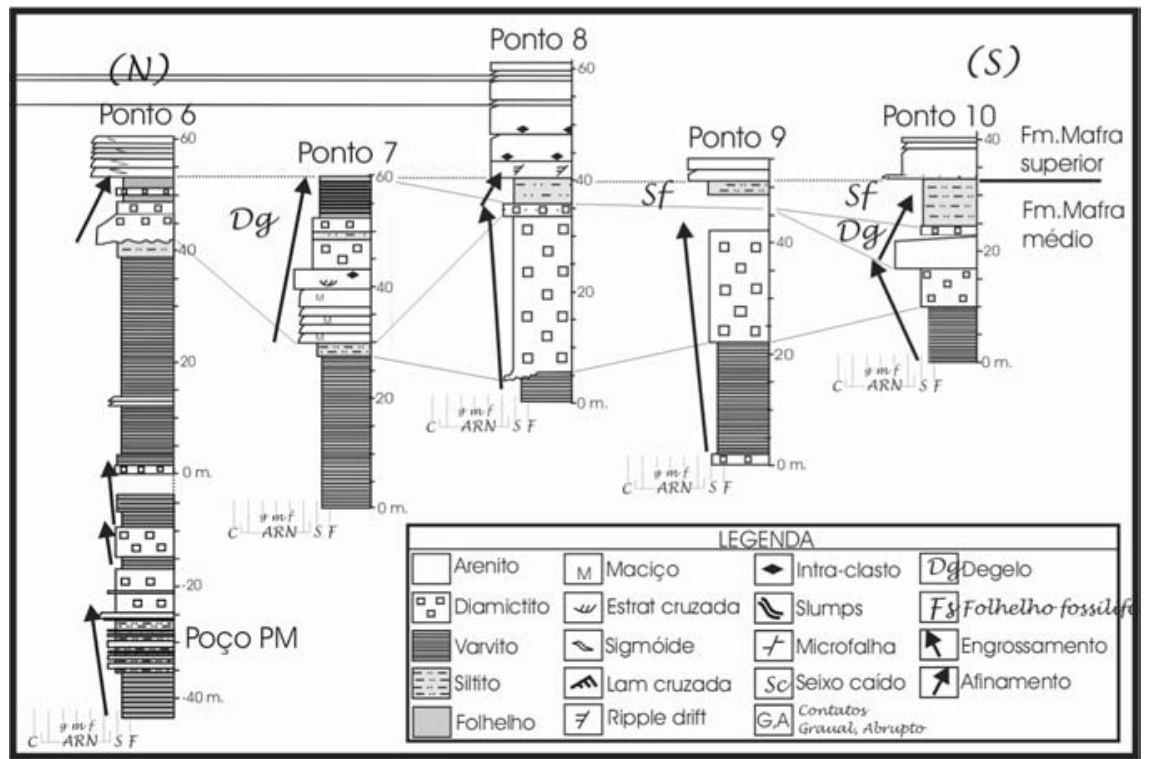

Figura 8 - Seção estratigráfica dos pontos 6 a 10, destacando a correlação dos ciclos granocrescente e granodecrescente do Mafra inferior. Notar o Datum no contato Arenito sigmoidal do Mafra Superior, com o varvito ou siltito fossilífero do Mafra Inferior. Ponto 6 composto com a sondagem PM-6.

vel de base baixo). Recobrindo erosivamente a seção anterior, ocorrem os arenitos sigmoidais (As) ou maciços/ritmicos da Formação Mafra-Superior, já caracterizando a base da terceira seqüência deposicional do Grupo Itararé na borda leste da bacia do Paraná.

\section{Agradecimentos}

Esse trabalho é parte da Tese de Doutoramento que o primeiro autor desenvolve junto à UNESP e que está sendo financiado pelo CNPq, ao qual agradece. Especial agradecimento é devido ao Dr. Victor Dequech, e à Fundação Victor Dequech, cujas sondagens proporcionaram novos horizontes à pesquisa sobre deposição glacial e que irão enriquecer a presente tese.

\section{Referências Bibliográficas}

CANUTO, J.R. Origem dos diamictitos $e$ de rochas associadas do Sub-Grupo Itararé, no sul do Estado do Paraná e norte do Estado de Santa Catarina. São Paulo: IGUSP, 1985. 187p. (Dissertação de Mestrado).

CASTRO, J.C. A evolução dos sistemas glacial, marinho e deltaico das formações Rio do
Sul e Rio Bonito/Mb. Triunfo (Eopermiano), sudeste da Bacia do Paraná.Rio Claro: UNESP/IGCE, 1991. 146p. (Tese de Doutorado).

CASTRO, J.C. Ciclos ou seqüências no arcabouço cronoestratigráfico da sucessão Itararé (Formação Taciba)-Rio Bonito (Membro Triunfo), Bacia do Paraná. In: SIMPÓSIO SOBRE CRONOESTRATIGRAFIA DA BACIA DO PARANÁ, 2, 1995. Porto Alegre. Boletim de Resumos Expandidos... Porto Alegre: UFRGS, 1995. p. 66-70.

FRANÇA, A.B., POTTER, P.E. Estratigrafia, ambiente deposicional e análise de reservatório do Grupo Itararé (Permocarbonífero), bacia do Paraná (Parte 1). Boletim de Geociências da Petrobrás. v.2, n.2/4, p. 147-191, 1988.

MACHADO, L.C. Fácies e arcabouço estratigráfico do Grupo Itararé em Alfredo Wagner, SC: sedimentação periglacial. Ouro Preto: UFOP, 1989. 163p. (Dissertação de Mestrado).

SCHNEIDER, R.L., MÜHLMANN, H., TOMMASI, E., MEDEIROS, R.A.A., DAEMON, R.F., NOGUEIRA, A.A. Revisão estratigráfica da bacia do Paraná. In: CONG. BRAS. GEOL., 28, 1974. Porto Alegre. Anais... Porto Alegre: SBG, 1974. v. 1, p. 41-65.

WEINSCHÜTZ, L.C. Análise estratigráfica e faciológica do Grupo Itararé na região de Mafra/SC e Rio Negro/PR, borda leste da Bacia do Paraná. Rio Claro: UNESP/ IGCE, 2001. 59p. (Tese de Mestrado).

\section{Artigo recebido em 23/01/2004 e} aprovado em 18/08/2004. 